\section{Treatment of foodborne botulism in current clinical toxicology}

\author{
Afshin Mohammad Alizadeh, 1 \\ Nasim Zamani 2 \\ 1Department of Bone Marrow \\ Transplantation, Taleghani Hospital, \\ Shahid Beheshti University of Medical \\ Sciences; 2Department of Forensic \\ Medicine and Clinical Toxicology, Tehran \\ University of Medical Sciences, Tehran, \\ Iran
}

\begin{abstract}
Dear Editor
We read with interest the case presented by Lonati D. et al. entitled Fatal course of foodborne botulism in an eight-month old infant being published in one of the recent issues of Pediatr Report. ${ }^{1}$ The authors have presented an 8-month-old female presenting to them with poor oral intake, weak cry, and extremely weak muscular body control. After some conservative treatments, they suspected the diagnosis of botulism and began to treat the patient with trivalent botulinum antitoxin,
\end{abstract}

administration of activated charcoal, and oral prostigmine as well as the routine conservative therapies. Although an interesting case, some concerns rise about the management of this patient. First of all, according to the available clinical toxicology textbooks, in cases of severe botulism, whole bowel irrigation (WBI) with polyethylene glycol may have a role in gastric decontamination. ${ }^{2}$ In such a severe case of toxicity, WBI could be an appropriate adjunctive option of gastrointestinal decontamination and would be better to be tried. Secondly, trivalent antitoxin must be used immediately upon consideration of the disease in both symptomatic and asymptomatic individuals recently exposed to a presumptive food source. ${ }^{2}$ This is while in this case, trivalent antitoxin has been initiated about 10 hours after laboratory confirmation of poisoning. This means that this patient has lost the very few first golden hours for treatment. Thank you for this interesting case.

\section{References}

1. Lonati D, Locatelli CA, Fenicia L, et al. Fatal course of foodborne botulism in an eight-month old infant. Pediatr Rep
Correspondence: Nasim Zamani, Hazrat Rasoul Akram Hospital, Niayesh Street, Sattar-Khan Ave., 1445613131, Tehran, Iran.

Tel. +98.216.655.1201.

E-mail: nasim.zamani@gmail.com

Key words: foodborne botulism, treatment, toxi cology.

Conflict of interests: the author reports no potential conflict of interests.

Received for publication: 23 April 2012.

Accepted for publication: 18 May 2012.

This work is licensed under a Creative Commons Attribution NonCommercial 3.0 License (CC BYNC 3.0).

(C) Copyright N. Zamani, 2012

Licensee PAGEPress, Italy

Pediatric Reports 2012; 4:e22

doi:10.4081/pr.2012.e22

2011;3:e31.

2. Goldfrank LR, Flomenbaum NE. Botulism. In: Flomenbaum NE, Goldfrank LR, Hoffman RS, et al. Goldfrank's Toxicologic Emergencies. 8th $^{\text {th }}$ McGraw-Hill; 2006:715-27. 